Fourth International Conference on Sustainable Construction Materials and Technologies http://www.claisse.info/Proceedings.htm

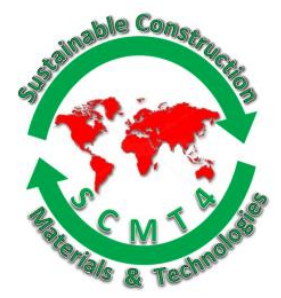

\author{
SCMT4
}

Las Vegas, USA, August 7-11, 2016

\title{
Mechanical Performance and Flow of Sustainable Alkali-Activated Slag Concrete
}

\author{
Alexandre Rodrigue ${ }^{1 \mathrm{a}}$, Josée Duchesne ${ }^{1 \mathrm{~b}}$, and Benoît Fournier ${ }^{1 \mathrm{c}}$ \\ ${ }^{1}$ Research Center on Concrete Infrastructures (CRIB), Département de géologie et génie géologique, 1065, \\ avenue de la médecine, Québec (QC), Canada G1V 0A6, Université Laval \\ ${ }^{1 a}$ Email: <alexandre.rodrigue.3@ulaval.ca>, ${ }^{1 b}$ Email: <Josee.Duchesne@ggl.ulaval.ca〉, \\ ${ }^{1 c}$ Email: <benoit.fournier@ggl.ulaval.ca>.
}

\begin{abstract}
This paper evaluates the effects of different parameters on the compressive strength and flow against time for alkali-activated blast furnace slag concrete. Coarse aggregate proportions, fineness of precursor, water dosage, superplasticizer dosage and nature of alkaline activator were investigated. This study shows that within the different tested parameters, the nature of the alkaline activator and the added water dosage have the most critical effect on strength and flow development.
\end{abstract}

Sodium silicate combined with sodium hydroxide enables curing at $23^{\circ} \mathrm{C}$ with strength values exceeding 30 $\mathrm{MPa}$ whereas concretes activated with sodium hydroxide need heating to achieve similar values. $\mathrm{Na}_{2} \mathrm{SiO}_{3} / \mathrm{NaOH} 8 \mathrm{M}$ ratios of $0.5,0.75$ and 1.0 resulted in compressive strength values of 30.6, 45.1 and 47.0 $\mathrm{MPa}$ at 3 days, respectively, for specimens kept at $38^{\circ} \mathrm{C}$ for the first 24 hours.

Increasing the water added to the mixture triggers a decrease in strength; however, the use of a naphthalenebased superplasticizer allows a reduction of water added to the mixture and results in increasing compressive strength. Increasing both the water content and the naphthalene-based superplasticizer dosage allows to maintain flowable concrete conditions over an extended period of time. The rate of flow loss against time for concretes activated with sodium silicate combined to sodium hydroxide was lower than the rate of flow loss of concretes using sodium hydroxide only.

An optimal alkali-activated slag concrete mix design with added water dosage of $72 \mathrm{~kg} / \mathrm{m}^{3}$, no superplasticizer, a $\mathrm{Na}_{2} \mathrm{SiO}_{3} / \mathrm{NaOH} 8 \mathrm{M}$ ratio of 0.5 , a sand content of $670 \mathrm{~kg} / \mathrm{m}^{3}$, a coarse aggregate content of $1040 \mathrm{~kg} / \mathrm{m}^{3}$ (40\% 14-20 mm, $30 \% 10-14 \mathrm{~mm}$ and $30 \% 5-10 \mathrm{~mm}$ ) and a total binder content of $400 \mathrm{~kg} / \mathrm{m}^{3}$ gave flow values of $155 \mathrm{~mm}$ after 30 minutes, $100 \mathrm{~mm}$ after 60 minutes and strength values of $38.7 \mathrm{MPa}$ (3 days) and 41.9 $\mathrm{MPa}$ (7 days). 


\section{INTRODUCTION}

Production of Portland cement has a strong environmental impact. Recent studies demonstrate that 5 to $7 \%$ of human produced $\mathrm{CO}_{2}$ results from Portland cement production (Barcelo and al., 2013). Global waste management is also an issue of growing concern since recent estimates note that 3.5 million tons of waste are produced every day on earth and are predicted to increase to 6 million tons by 2025 (Hoornweg \& BhadaTata, 2012). The use of industrial by-products like fly ash or blast furnace slag should be investigated as binders to replace Portland cement beyond conventional replacement levels in concrete to reduce $\mathrm{CO}_{2}$ production and waste disposal.

Aluminosilicate based industrial by-products offer a good potential as a binding material in concrete and mortars. Blast furnace slag in particular results from the melting of iron ore, coke and a flux (limestone or dolomite) in a blast furnace. The coproduct formed during this process is primarily composed of silicates and aluminosilicates (U.S. Department of Transportation, 2012). Blast furnace slag is already widely used as a cementous replacement material in concrete but a total Portland cement replacement is also possible. In order to obtain equivalent or superior blast furnace slag concrete, an alkaline activating solution must be used during mixing to catalyse the dissolution and polymerization of the precursor which has otherwise a latent hydraulic reactivity (Lecomte et al., 2006). The alkali-activation allows the formation of a dense and solid matrix which binds the different constituents of the alkali-activated concrete. The reaction is believed to follow a four-step mechanism which include: dissolution of the precursor, nucleation and growth of the initial binding phases, mechanical binding of the phases and diffusion of the reactive species (Panias \& al., 2007). Binders formed during the alkali-activation of slag precursors are mostly composed of a C-A-S-H gel that resembles to the C-S-H type gel of conventional Portland cement concrete but incorporates aluminium (A in C-A-S-H) in its chemical structure (Bernal \& Provis, 2014; Puertas \& al., 2011). Widespread use of blast furnace slag concrete depends on the ability to produce a material that offers equivalent or superior mechanical performances and adequate flow for transport and casting.

\section{EXPERIMENTAL PROGRAM}

Materials. Two different blast furnace slag precursors were used with similar composition but different fineness. Table 1 presents the chemical composition of these precursors. Slag 1 is a grade 80 blast furnace slag from Stoney Creek, Canada and slag 2 a grade 120 blast furnace slag from Lafarge North America Inc. in Chicago, USA. Three different types of activators were used: an $8 \mathrm{M}$ sodium hydroxide solution, an $8 \mathrm{M}$ sodium hydroxide and sodium silicate solution and a $4 \mathrm{M}$ sodium hydroxide and sodium silicate solution. Different $\mathrm{Na}_{2} \mathrm{SiO}_{3} / \mathrm{NaOH}$ mass ratios were tested for the combined activators. All activators were prepared at least 24 hours before mixing to eliminate the heat contribution of the exothermic reaction that results of the dissolution of sodium hydroxide pellets and the combination of sodium hydroxide and sodium silicate. Table 2 illustrates the chemical composition of the grade $\mathrm{N}$ sodium silicate used.

Table 1. Composition of Blast Furnace Slag Precursors in Major Oxides \%

\begin{tabular}{|l|c|c|c|c|c|c|c|c|c|}
\hline Oxides, wt. \% & $\mathbf{S i O}_{2}$ & $\mathbf{A l}_{\mathbf{2}} \mathbf{O}_{\mathbf{3}}$ & $\mathbf{C a O}$ & $\mathbf{M g O}$ & $\mathbf{F e}_{2} \mathbf{O}_{\mathbf{3}}$ & $\mathbf{N a}_{2} \mathbf{O}$ & $\mathbf{K}_{\mathbf{2}} \mathbf{O}$ & $\mathbf{T i O}_{\mathbf{2}}$ & $\mathbf{L O I}$ \\
\hline Slag 1 & 37.74 & 10.75 & 36.20 & 12.62 & 0.50 & 0.41 & 0.49 & 0.91 & -0.8 \\
\hline Slag 2 & 37.77 & 11.10 & 38.69 & 9.78 & 0.42 & 0.26 & 0.43 & 0.51 & 0.40 \\
\hline
\end{tabular}




\section{Table 2. Chemical Composition of Sodium Silicate (grade N) in Major Oxides \%}

\begin{tabular}{|c|c|c|c|}
\hline Oxides, wt. $\%$ & $\mathbf{S i O}_{2}$ & $\mathbf{N a}_{2} \mathbf{O}$ & $\mathbf{H}_{2} \mathbf{O}$ \\
\hline Sodium silicate (grade N) & 28.70 & 9.04 & 62.26 \\
\hline
\end{tabular}

A granitic gneiss coarse aggregate (Carrière LT, Ange-gardien, Quebec, Canada) of $20 \mathrm{~mm}$ maximum particle size with water absorption of $0.72 \%$ was used. The fine aggregate was a natural granitic sand with a water absorption of $0.64 \%$. All aggregates were dried at $110^{\circ} \mathrm{C}$ for 24 hours before mixing. The superplasticizer used was the Eucon 37 of Euclid Canada. The product is a naphthalene-based superplasticizer and was kept at all times at a temperature of $23^{\circ} \mathrm{C}$ in a hermetic container.

Mix proportions and sample conditioning. All concretes were produced with the same activator-to-binder ratio of 0.35 and a total binder content of $400 \mathrm{~kg} / \mathrm{m}^{3}$. Aggregate proportions, fineness of precursor, water dosage, superplasticizer dosage and nature of alkaline activator were investigated. Table 3 shows the different aggregate proportions tested.

\section{Table 3. Aggregate Proportions Tested in Concrete}

\begin{tabular}{|l|c|c|c|c|c|}
\hline \multirow{2}{*}{ Mix } & Sand $\mathbf{( k g / \mathbf { m } ^ { 3 } )}$ & \multicolumn{4}{|c|}{ Coarse aggregate $\mathbf{( k g / \mathbf { m } ^ { 3 } )}$} \\
\cline { 2 - 6 } & - & $5-10 \mathrm{~mm}$ & $10-14 \mathrm{~mm}$ & $14-20 \mathrm{~mm}$ & total \\
\hline A & 670 & 347 & 347 & 347 & 1041 \\
\hline B & 670 & 312 & 312 & 416 & 1040 \\
\hline C & 543 & 634 & 363 & 272 & 1269 \\
\hline
\end{tabular}

Subsequent mix designs tested incorporated the aggregate proportions (A, B or C) with the best compressive strength values in concrete. Added water dosages of 14, 18, 22 and 26wt.\% of binder content and superplasticizer dosages of 2, 4, 6 and $8 \mathrm{wt} . \%$ of binder content were tested in concrete to determine their effect on compressive strength and flowability against time. Activators combining sodium hydroxide (8 mol/L) and sodium silicate were tested for $\mathrm{Na}_{2} \mathrm{SiO}_{3}$ to $\mathrm{NaOH}$ ratios of $0.5,0.75$ and 1.0.

Curing temperatures of 80,38 and $23^{\circ} \mathrm{C}$ were tested in compressive strength after 3 days. A 24 hour period was fixed for heat curing at 80 and $38^{\circ} \mathrm{C}$ and samples were afterwards kept at $23^{\circ} \mathrm{C}$ and $50 \%$ relative humidity until testing. All samples were kept in a non-sealed plastic bag to avoid excessive evaporation but also to resemble on-the-field curing.

\section{Experimental procedures}

Mixing sequence. Sand and coarse aggregates are mixed together for 1 minutes before adding the binder. An additional 1 minute of mixing is done after adding the binder and before the incorporation of the liquid constituents. Finally, the activator, water and superplasticizer are added and mixed for an additional 4 minutes before the first slump test or casting.

Compressive strength. Compressive strength tests were done following CSA A23.2-9C and carried out at 3 and 7 days. All concrete samples were prepared following CSA A23.2-3C and consisted in cylinders of 100 $\mathrm{mm}$ of diameter and $200 \mathrm{~mm}$ of length. The testing was done using a charging rate of $2000 \mathrm{~N} / \mathrm{s}$. 
Flow against time. Flow tests were done following CSA A23.2-5C at times of 4, 10, 15, 20, 30, 40, 50, 60, 70 and 80 minutes after the mixing sequence or until a flow value of $40 \mathrm{~mm}$ was obtained. The values of flow against time are then plotted to illustrate flow evolution with time and stability of the fresh concrete.

Scanning electron microscope (SEM). SEM observations were done at Laval University. The samples were approximately of $1 \mathrm{~cm}^{3}$ and were dried at $70^{\circ} \mathrm{C}$ for 24 hours before analyse. The samples were covered with a thin gold-palladium layer and an electron beam of $15 \mathrm{KeV}$ was used.

\section{RESULTS AND DISCUSSION}

Aggregate proportions. Compressive strength was evaluated for mix designs A, B and C with both slags and two different activators. Two different $\mathrm{Na}_{2} \mathrm{SiO}_{3}$ to $\mathrm{NaOH} 8 \mathrm{M}$ ratios of 0 and 1 were tested for each slag with an added water dosage of $12 \mathrm{wt} . \%$ of binder content and superplasticizer dosage of $2 \mathrm{wt} . \%$ of binder content. Figure 1 shows the effect of aggregate proportions A, B and C on the compressive strength of concrete using respectively slag 1 (figure 1a) and 2 (figure 1b) as binders. The concrete samples were cured at $23^{\circ} \mathrm{C}$ for the first 24 hours followed by a 24 hour period at $80^{\circ} \mathrm{C}$ and then kept at $23^{\circ} \mathrm{C}$ and $50 \%$ relative humidity until testing after 3 days.

For an activator $\mathrm{Na}_{2} \mathrm{SiO}_{3}$ to $\mathrm{NaOH} 8 \mathrm{M}$ ratio of 0 , mix B allows the highest values of compressive strength with both slags. For an activator $\mathrm{Na}_{2} \mathrm{SiO}_{3}$ to $\mathrm{NaOH} 8 \mathrm{M}$ ratio of 1 , mix A allows the highest value of compressive strength when using slag 1 as binder and mix $\mathrm{C}$ when using slag 2 as binder. These results suggest that coarse aggregate proportions do not significantly affect mechanical strength of slag concrete.

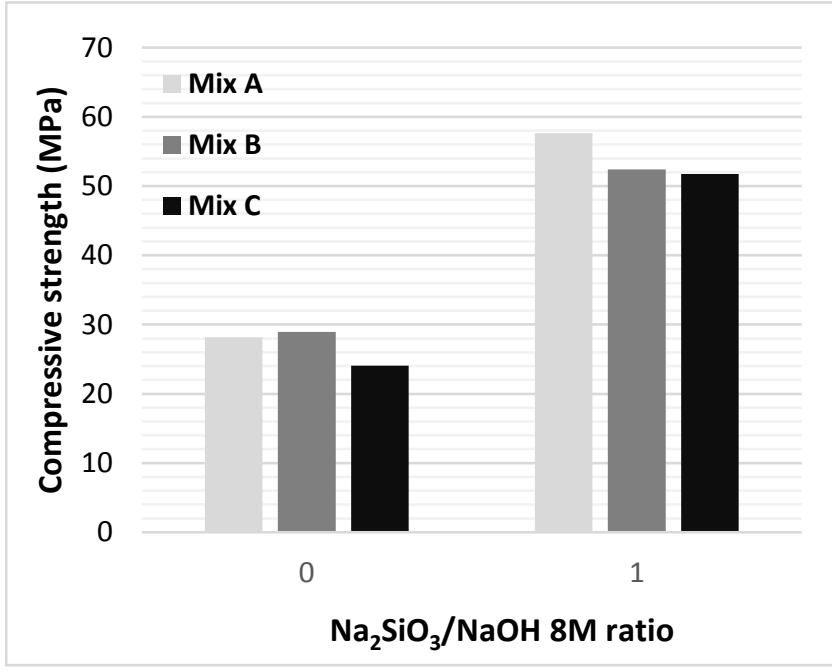

Figure 1a. Effect of aggregate proportions and activator composition on compressive strength of slag concrete using slag \#1 as binder after 3 days

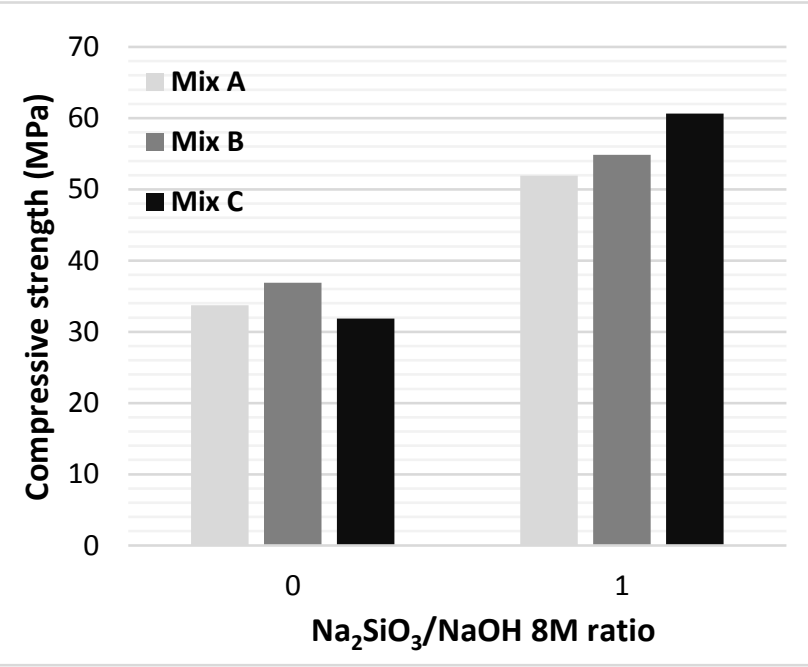

Figure 1b. Effect of aggregate proportions and activator composition on compressive strength of slag concrete using slag \#2 as binder after 3 days 
Fineness of precursor. As shown in the previous section in figures $1 \mathrm{a}$ and $1 \mathrm{~b}$, a higher fineness of the precursor results in higher values of compressive strength. In most cases, the use of slag 2 as precursor enables higher values of compressive strength after 3 days. The only exception is for the concrete samples made with an activator with a $\mathrm{Na}_{2} \mathrm{SiO}_{3}$ to $\mathrm{NaOH} 8 \mathrm{M}$ ratio of 1 and aggregate proportion mix $\mathrm{A}$. In general, these results suggest that greater specific area of precursor enables greater strength of the binding phase in concrete in thus, potentially better dissolution and polymerization.

Nature of activator and curing temperature. The results presented in figure 2 show the influence of the $\mathrm{Na}_{2} \mathrm{SiO}_{3}$ to $\mathrm{NaOH} 8 \mathrm{M}$ ratio on compressive strength of slag concrete for different curing temperatures. Increasing the $\mathrm{Na}_{2} \mathrm{SiO}_{3}$ to $\mathrm{NaOH} 8 \mathrm{M}$ ratio $(0.5,0.75$ and 1.0) results in an increase in compressive strength values. Furthermore, two different curing temperatures of 38 and $80^{\circ} \mathrm{C}$ for the first 24 hours were applied. Added water dosage, superplasticizer dosage and activator to binder ratio were respectably of $14 \mathrm{wt} . \%$ of binder content, $2 \mathrm{wt}$. $\%$ of binder content and 0.35 .

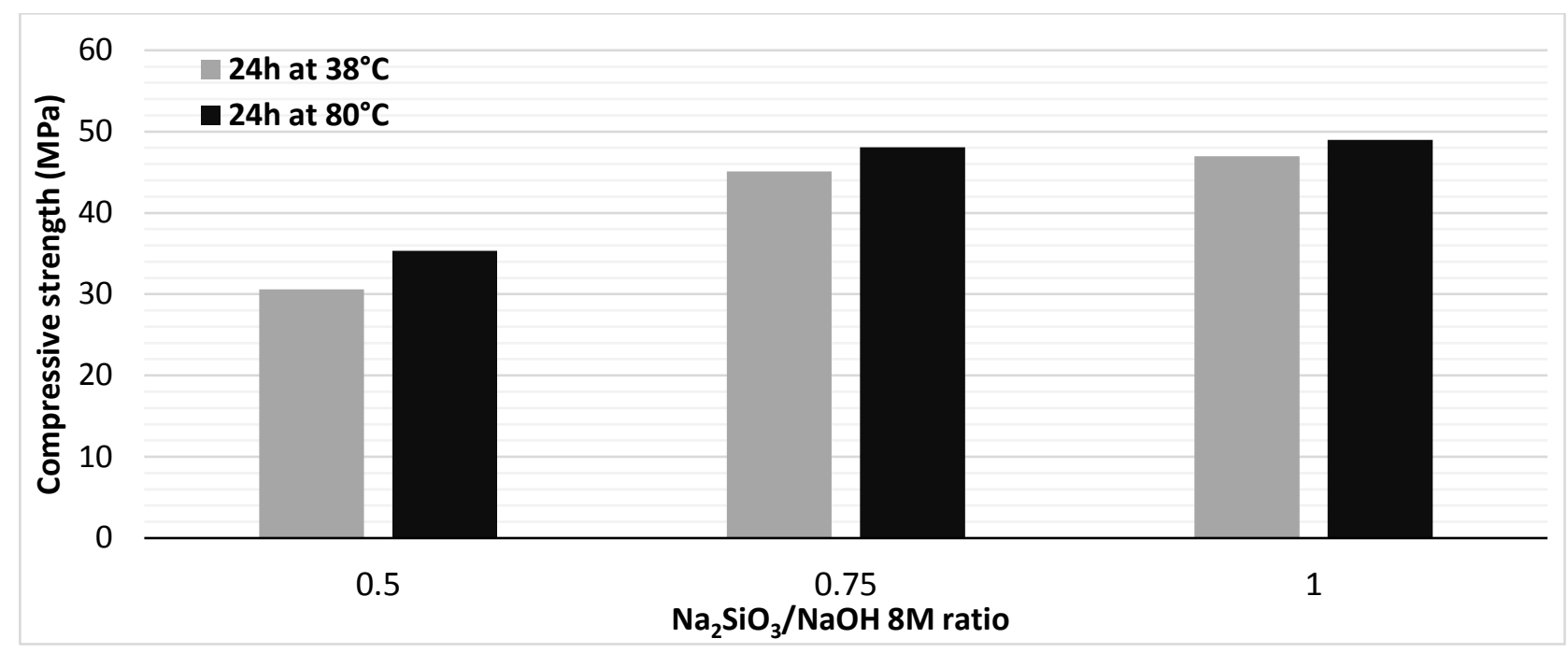

\section{Figure 2. Effect of $\mathrm{Na}_{2} \mathrm{SiO}_{3}$ to $\mathrm{NaOH} 8 \mathrm{M}$ ratio and curing temperature on compressive strength of slag (\# 1) concrete}

The compressive strength values measured at 3 days for slag concretes with a 24 hour curing period at 38 and $80^{\circ} \mathrm{C}$ do not show a significant difference and the observed difference seems to decrease with increasing sodium silicate dosage. Concrete samples with activator $\mathrm{Na}_{2} \mathrm{SiO}_{3}$ to $\mathrm{NaOH} 8 \mathrm{M}$ ratio of 0.75 and superplasticizer dosage of $4 \mathrm{wt} . \%$ were also cured at $23^{\circ} \mathrm{C}$ and $50 \%$ relative humidity throughout the entire period before testing and resulted in an average compressive strength value of $43.2 \mathrm{MPa}$ was measured at 3 days. Concrete samples with activator $\mathrm{Na}_{2} \mathrm{SiO}_{3}$ to $\mathrm{NaOH} 8 \mathrm{M}$ ratio of 0 , no superplasticizer and curing temperature of $23^{\circ} \mathrm{C}$ result in compressive strength values below $20 \mathrm{MPa}$ suggesting that sodium silicate allows good mechanical performance for samples cured at ambient temperature.

Further testing has been done decreasing the sodium hydroxide concentration from 8 to $4 \mathrm{~mol} / \mathrm{L}$ in the activator and maintaining a $\mathrm{Na}_{2} \mathrm{SiO}_{3}$ to $\mathrm{NaOH}$ ratio of 0.75 . With a curing temperature of $23^{\circ} \mathrm{C}$ throughout the 
entire period before testing, no final set was possible after 3 days following the casting of the concrete samples. However, the obtained compressive strength after 7 days was of $38.1 \mathrm{MPa}$ suggesting that the activator concentration in regards to the sodium hydroxide constituent is mainly responsible for retardation in strength gain but still allows good compressive strength values.

Added water dosage. Slag concrete samples cured at $23^{\circ} \mathrm{C}$ and $50 \%$ relative humidity showed lower compressive strength values when activated with $\mathrm{NaOH} 8 \mathrm{M}$ solution without sodium silicate. Figure 5 shows the effect of added water during mixing on compressive strength values after 7 days for slag concrete activated with a $\mathrm{NaOH} 8 \mathrm{M}$ solution and cured at $23^{\circ} \mathrm{C}$. An increase in added water during mixing triggers a decrease in compressive strength values. Also, ambient temperature curing of slag concrete samples using a $\mathrm{NaOH} 8 \mathrm{M}$ solution without sodium silicate results in low compressive strength values $(<20 \mathrm{MPa})$. Figure 6 shows the effect of added water dosage during mixing on slump values against time.

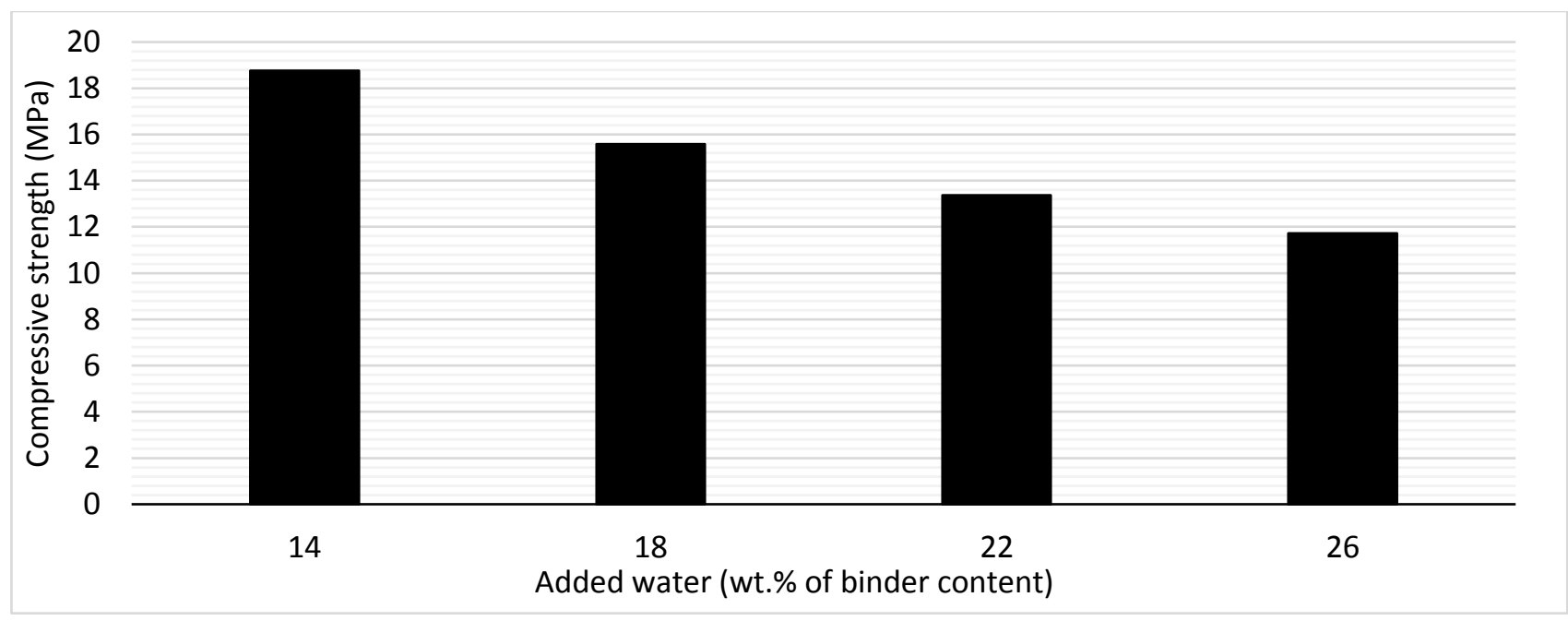

Figure 3. Compressive strength values at 7 days for slag 1 concrete activated with $\mathrm{NaOH} 8 \mathrm{M}$ solution

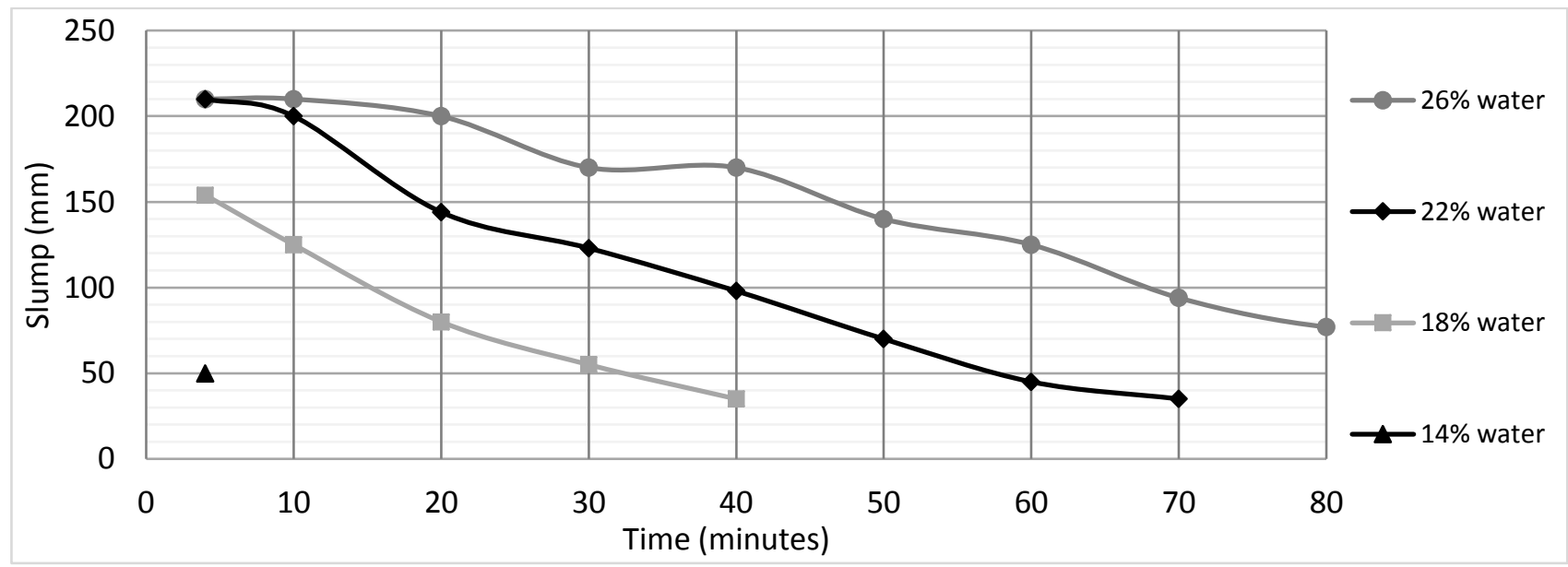

Figure 4. Slump against time for slag 1 concrete activated with $\mathrm{NaOH} 8 \mathrm{M}$ solution 
An increase in added water during mixing reduces the rate of slump lost against time which suggests that water directly affects setting time. Further investigations have been done to pinpoint the effects of added water on microstructure and thus, try to explain the decreasing compressive strength values observed with increasing water dosage. Figure 7 shows two images obtained by a scanning electron microscope which illustrate the matrix texture of concrete pastes that incorporate an added water dosage of 14 and $18 \mathrm{wt} \%$ of binder content.
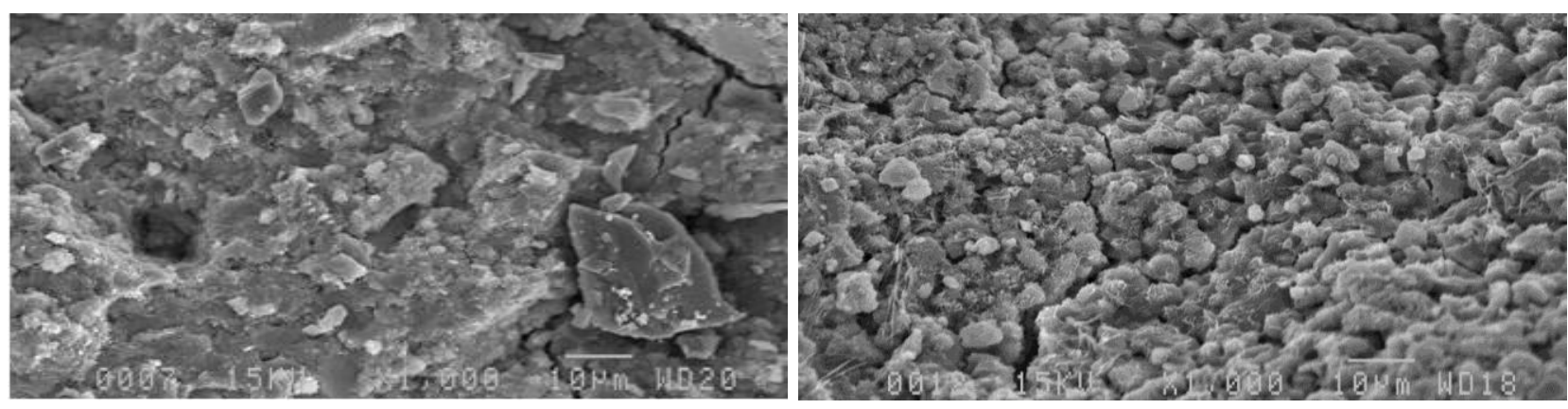

Figure 8. Scanning electron microscope images of concrete pastes that incorporate an added water dosage of 14 (left) and 18 (right) wt.\% of binder content

The paste with the lowest added water content (14\%) shows a more regular and homogenous texture with few unreacted angular slag particles and a small amount of partly reacted slag particles. On the other hand, the paste with an added water dosage of $18 \mathrm{wt} . \%$ of binder content is characterized by a more granular and irregular texture. The granular texture observed suggests the presence of abundant partly reacted slag particles and thus, an uncomplete geopolymerization of the matrix.

The effect of added water dosage during mixing was also investigated in concretes activated using a combination of $\mathrm{NaOH} 8 \mathrm{M}$ and sodium silicate. Figure 8 illustrates the slump lost for concretes using an activator with $\mathrm{Na}_{2} \mathrm{SiO}_{3}$ to $\mathrm{NaOH}$ ratio of 0.5 .

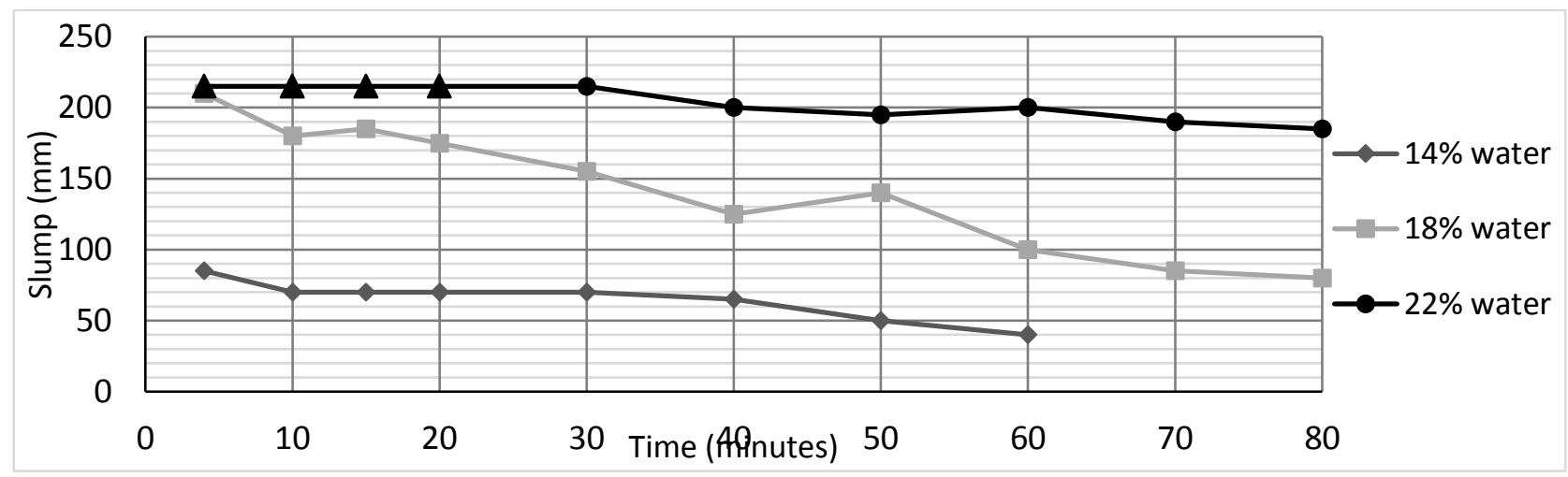

Figure 9. Effect of added water during mixing on slump against time for slag concrete activated with a $\mathrm{NaOH} 8 \mathrm{M}$ and sodium silicate solution $\left(\mathrm{Na}_{2} \mathrm{SiO}_{3}\right.$ to $\mathrm{NaOH}$ ratio of 0.5$)$ and cured at $23^{\circ} \mathrm{C}$ (triangles: lowest minimal value based on first possible measurement due to excessive flow) 
Again, an increase in added water during mixing reduces the rate of slump lost against time but the use of sodium silicate in the activator solution also allows a decrease in slump lost for identical added water dosages when compared to concrete activated with only a $\mathrm{NaOH} 8 \mathrm{M}$ solution and cured at $23^{\circ} \mathrm{C}$. Sodium silicate also seems to stabilize and decrease the rate of slump lost against time. This allows the use of lower added water dosages for a desired flow and thus, the possibility to obtain higher compressive strength values in concrete. The concrete mix with an added water dosage of $18 \mathrm{wt} . \%$ of binder content shown in figure 8 has been redone and casted at a slump value of $100 \mathrm{~mm}$ to be tested for compressive strength. The average compressive strength values of $38.7 \mathrm{MPa}$ after 3 days and $41.9 \mathrm{MPa}$ after 7 days were obtained. This mix design also allows a slump value of $100 \mathrm{~mm}$ after 60 minutes following the mixing procedure without the use of a superplasticizer or any admixture.

Superplasticizer dosage. The effect of a naphthalene-based superplasticizer on slump lost was evaluated and results are shown in figure 9. The concrete mixes tested were done using an activator with a $\mathrm{Na}_{2} \mathrm{SiO}_{3}$ to $\mathrm{NaOH}$ ratio of 0.5 and an added water dosage of $14 \mathrm{wt} . \%$ of binder content.

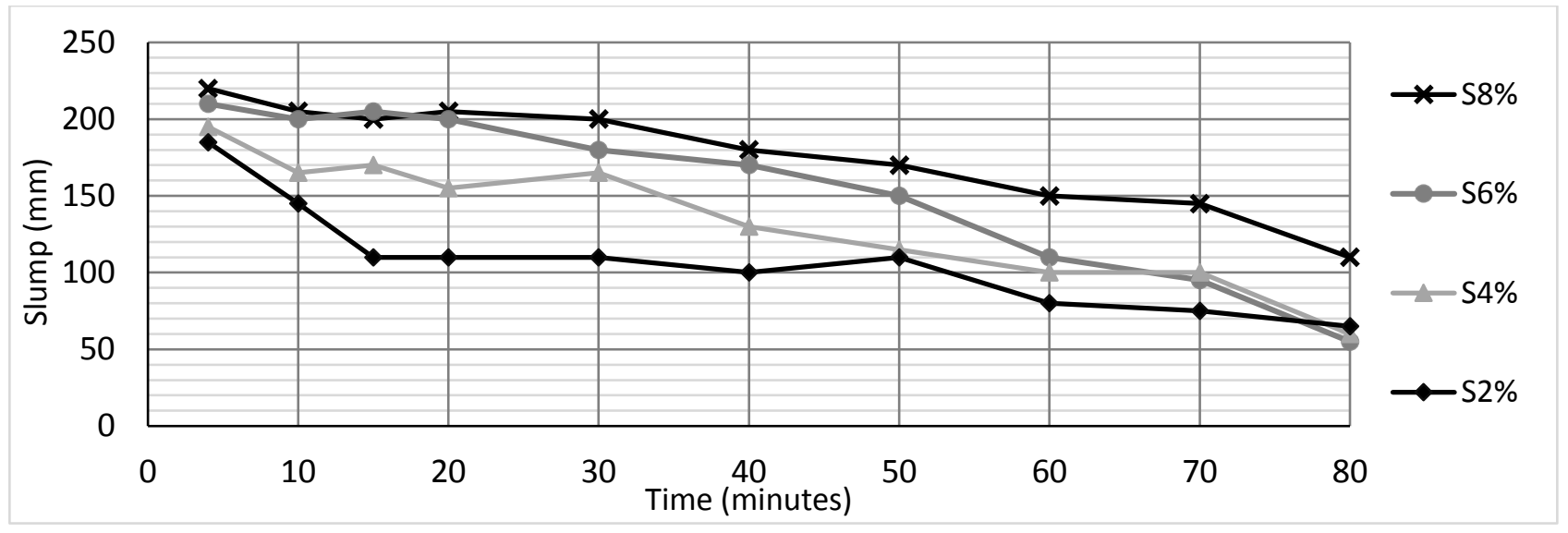

\section{Figure 10. Effect of superplasticizer dosage on slump against time for slag concrete activated with a $\mathrm{NaOH} 8 \mathrm{M}$ and sodium silicate solution $\left(\mathrm{Na}_{2} \mathrm{SiO}_{3}\right.$ to $\mathrm{NaOH}$ ratio of 0.5$)$ and cured at $23^{\circ} \mathrm{C}$}

The use of this superplasticizer significantly enhances the flow of the slag concrete. The lowest dosage tested allows to maintain a slump value over $100 \mathrm{~mm}$ for up to approximately 50 minutes after the mixing procedure.

\section{CONCLUSION}

The effects of coarse aggregate proportions, fineness of precursor, water dosage, superplasticizer dosage and nature of alkaline activator on the development of compressive strength and flow against time for alkaliactivated blast furnace slag concrete were investigated. This study allows the following conclusions to be drawn:

Addition of sodium silicate in the activator solution enables curing at $23^{\circ} \mathrm{C}$, compressive strength values over $30 \mathrm{MPa}$ and enhanced stability of flow of slag concrete. It also allows good flow for a longer period of time which can facilitate casting. 
- Increasing the added water dosage during mixing enables higher slump values for a given time and retards slump loss but decreases compressive strength values.

- Increasing the fineness of the precursor from grade 80 to 120 results in an increase in compressive strength values for concretes activated without sodium silicate. The effect of fineness for concretes activated with sodium silicate will need further investigation in order to explain the results obtained.

- Coarse aggregate proportions do not seem to significantly affect compressive strength values.

- Increasing the naphthalene-based superplasticizer dosage enables higher slump values, extends and stabilizes slump loss.

- An optimal alkali-activated slag concrete mix design with added water dosage of $72 \mathrm{~kg} / \mathrm{m}^{3}$, no superplasticizer, a $\mathrm{Na}_{2} \mathrm{SiO}_{3} / \mathrm{NaOH} 8 \mathrm{M}$ ratio of 0.5 , a sand content of $670 \mathrm{~kg} / \mathrm{m}^{3}$, a coarse aggregate content of $1040 \mathrm{~kg} / \mathrm{m}^{3}$ (40\% 14-20 mm, $30 \% 10-14 \mathrm{~mm}$ and $30 \% 5-10 \mathrm{~mm}$ ) and a total binder content of $400 \mathrm{~kg} / \mathrm{m}^{3}$ gave flow values of $155 \mathrm{~mm}$ after 30 minutes, $100 \mathrm{~mm}$ after 60 minutes and strength values of $38.7 \mathrm{MPa}$ (3 days) and 41.9 $\mathrm{MPa}$ (7 days).

\section{ACKNOWLEDGEMENTS}

This study has been supported by the National Science and Engineering Research Council of Canada (NSERC) and by the Fonds de recherche du Québec - nature et technologies (FRQ-NT). The authors would also like to acknowledge Jean-Benoit Darveau for his assistance in the preparation of the concrete samples.

\section{REFERENCES}

Barcelo, L., Kline, J., Walenta, G., \& Gartner, E. (2013). Cement and carbon emissions. Materials and Structures, 47(6), 1055-1065.

Bernal, S. a., \& Provis, J. L. (2014). Durability of alkali-activated materials: Progress and perspectives. Journal of the American Ceramic Society, 97(4), 997-1008.

Blast Furnace Slag - Material Description - User Guidelines for Waste and Byproduct Materials in Pavement Construction - FHWA-RD-97-148. (n.d.). Retrieved November 23, 2015

Hoornweg, D., \& Bhada-Tata, P. (2012). What a waste: a global review of solid waste management. World Bank, Washington DC.

Lecomte, I., Henrist, C., Liégeois, M., Maseri, F., Rulmont, a., \& Cloots, R. (2006). (Micro)-structural comparison between geopolymers, alkali-activated slag cement and Portland cement. Journal of the European Ceramic Society, 26(16), 3789-3797.

Long-term, G. C., Wallah, S. E., \& Rangan, B. V. (2006). LOW-CALCIUM FLY ASH-BASED By Curtin University of Technology.

Panias, D., Giannopoulou, I. P., \& Perraki, T. (2007). Effect of synthesis parameters on the mechanical properties of fly ash-based geopolymers. Colloids and Surfaces A: Physicochemical and Engineering Aspects, 301(1-3), 246-254.

Puertas, F., Palacios, M., Manzano, H., Dolado, J. S., Rico, a., \& Rodríguez, J. (2011). A model for the CA-S-H gel formed in alkali-activated slag cements. Journal of the European Ceramic Society, 31(12), 2043-2056. 